\title{
Indução de Resistência à Brusone em Folhas de Arroz por Isolado Avirulento de Magnaporthe oryzae
}

\author{
Marta C.C. Filippi ${ }^{1}$, Gisele B. Silva ${ }^{2}$ \& Anne S. Prabhu ${ }^{1}$ \\ ${ }^{1}$ Embrapa Arroz e Feijão, Cx. Postal 179, CEP 75375-000, Santo Antônio de Goiás, GO, Brasil, \\ e-mail: cristina@cnpaf.embrapa.br; ${ }^{2}$ Universidade Federal Rural da Amazônia, Av. Presidente Tancredo Neves, 2508 \\ CEP 66077-530, Belém, PA, Brasil, e-mail: gisele.barata@ufra.edu.br
}

Autor para correspondência: Marta C.C. Filippi

FILIPPI, M.C.C., SILVA, G.B \& PRABHU, A.S. Indução de resistência à brusone em folhas de arroz por isolado avirulento de Magnaporthe oryzae. Fitopatologia Brasileira 32:387-392. 2007.

\begin{abstract}
RESUMO
A resistência a doenças pode ser induzida em plantas tanto por agentes abióticos como por agentes bióticos, por exemplo isolados avirulentos de patógenos. No presente trabalho objetivou-se determinar a concentração de um isolado avirulento (indutor) e o período necessário para induzir resistência em folhas de arroz a um isolado virulento de $M$. oryzae. Em casa de vegetação, plantas com 18 dias das cultivares Metica-1 e Cica-8 foram pulverizadas com um isolado indutor de resistência, nas concentrações de $0,10^{5}, 3 \times 10^{5}$ e $6 \times 10^{5}$ conídios. $\mathrm{mL}^{-1}$ em períodos que antecederam a inoculação do isolado virulento de 24, 48 e 72 horas. A indução da resistência manifestou-se na redução da área foliar afetada e no tipo de lesão. O grau de indução de resistência foi maior na cultivar Metica-1 do que na cultivar Cica-8, em relação a suas respectivas testemunhas. A indução da resistência em Cica- 8 foi superior quando o indutor foi aplicado 48 horas antes da aplicação do isolado virulento nas concentrações de $6 \times 10^{5}$ e $3 \times 10^{5}$ conídios. $\mathrm{mL}^{-1}$. Por outro lado, a indução de resistência em Metica-1 foi significativamente maior em todas as concentrações e períodos de aplicações do indutor quando comparados com a testemunha, mas não houve diferença entre os tratamentos de indução.
\end{abstract}

Palavras-chave adicionais: Oryza sativa, Pyricularia oryzae, resistência sistêmica adquirida.

\begin{abstract}
Induction of leaf blast resistance in rice by an avirulent isolate of Magnaporthe oryzae

The induction of disease resistance can be activated in plants with biotic and abiotic agents such as avirulent isolates of pathogens. The objective of this investigation was to determine the concentration of inducer isolate and the time required between the inoculation with inducer (avirulent isolate) and virulent isolate of Magnaporthe oryzae, for the induction of resistance in rice leaves. Eighteen-day-old plants of rice cultivars Metica-1 and Cica- 8 were sprayed in a greenhouse with an avirulent isolate utilized as inducer, at the concentrations of $0,10^{5}, 3 \times 10^{5}$ and $6 \times 10^{5}$ conidia $\mathrm{mL}^{-1}$; sprayed 24,48 , and 72 hours prior to inoculation with virulent isolate. The induction of resistance was manifested in the reduction of leaf area affected and lesion type. The degree of induced resistance was greater in cultivar Metica- 1 than in cultivar Cica- 8 in relation to respective controls. The induction of resistance was superior in Cica- 8 in treatments where inducers were applied 48 hours prior to inoculation with the virulent isolate, at concentrations of $6 \times 10^{5}$ and $3 \times 10^{5}$ conidia $\mathrm{mL}^{-1}$. On the other hand, the induction in Metica-1 was significantly higher in relation to control, at all concentrations and all periods of application of the inducer, and did not show differences between treatments.
\end{abstract}

Additional keywords: Oryza sativa, Pyricularia oryzae, Magnaporthe grisea, systemic acquired resistance.

\section{INTRODUÇÃO}

O Reino vegetal durante seu processo evolutivo desenvolveu diferentes mecanismos de defesa contra estresses, sejam bióticos ou abióticos, que acontecem em cadeia disparando uma rede de eventos, isoladamente ou em conjunto. Um destes eventos é a resistência sistêmica adquirida (RSA) que se caracteriza por ser um sistema imune nato e potente contra um largo espectro de patógenos (Jarosch et al., 1999). Ao induzir a resistência de um hospedeiro estimula-se a síntese de compostos de defesa conferida por genes presentes no genótipo do hospedeiro, que tanto pode ser expressa de forma localizada ou de forma sistêmica (RSA), e neste caso será efetiva em todas ou em quase todas as partes da planta. Os agentes indutores da resistência podem ser de natureza biótica ou abiótica (Schonebeck \& Steiner, 1997), como por exemplo, um isolado avirulento, uma injúria mecânica, ou mesmo um produto químico (Manandhar et al., 2000). O tratamento de sementes com ácido salicílico oferece proteção sistêmica contra à brusone em plântulas de arroz (Cai \& Zheng, 1997). Os fungicidas sistêmicos como diclorociclopropane, probenazole e tricyclazole ativam os mecanismos de defesa da planta (Manandhar et al., 1998).

A brusone do arroz (Oryza sativa), causada pelo ascomiceto Magnaporthe oryzae Barr (anamorfo Pyricularia grisea Cav.), ocorre em todas as regiões produtoras de arroz do mundo e é conhecida como uma das doenças mais destrutivas, causando danos de até $100 \%$. No Brasil, os danos em arroz de terras altas, chegaram em 59,6\% (Prabhu et al., 2003). No binômio M. oryzae e O. sativa a 
interação especializada entre o patótipo e a cultivar de arroz é explicada pela teoria gene a gene (Flor, 1971). De acordo com esta teoria, a reação de hipersensibilidade é o resultado de uma interação incompatível entre o gene de avirulência do patógeno e o gene de resistência do hospedeiro. Wang et al. (2007) desenvolveram marcadores moleculares, que vem sendo aplicado para o gene de resistência $P i$-ta, clonado por Jia e colaboradores (2000) da cultivar de arroz Yachiromichi. Pi-ta codifica uma proteina citoplasmática com sítios de ligação a nucleotídeos (NBS), que, putativamente, ao ligar-se ao produto processado do gene de avirulência $A V R$ Pita em Pyricularia grisea e ativa uma resposta de defesa da planta, provando assim a teoria gene a gene. A reação de hipersensibilidade caracteriza-se pela morte celular localizada no sítio de penetração do patógeno, produção de espécies reativas de oxigênio, fortificação da parede celular, acúmulo de calose e lignina, aumento da atividade de enzimas como chalcona isomerase e peroxidases, acúmulo de compostos antimicrobianos e fitoalexinas, indução de proteínas relacionadas a patogênese $(\mathrm{PR})$ e a síntese de metabólitos secundários (Schenck et al., 2000; Yang \& Dickman, 1999). Os genes para a síntese destes compostos de defesa citados acima encontram-se presentes em todos os genótipos (Kuc, 1995, Ribeiro do Vale et al., 2001). A diferença entre um genótipo resistente e suscetível está em como e quando a expressão destes genes será induzida. Numa interação incompatível, isto é, entre isolado avirulento e uma cultivar resistente, a presença de um receptor, codificado por este gene de resistência, desencadeia uma série de induções de outros genes de defesa, os quais expressam-se em tempo necessário para produzir um fenótipo resistente, após o reconhecimento do elicitor produto do gene de avirulência (Kuc \& Strobe, 1992; Ribeiro do Vale et al., 2001). Tanto nos casos de incompatibilidade como de compatibilidade, a expressão dos genes de defesa dependem da eficiência do hospedeiro em reconhecer a presença do patógeno através de mecanismos de percepção e transdução de sinais, que envolvem alterações transitórias no fluxo de íons e mudanças no estado de fosforilação de várias proteínas. Esse processo resulta na ativação de fatores de transcrição no núcleo da célula vegetal, com a expressão subsequente de genes de defesa (Guzzo, 2004)

Investigar a interação de $M$. oryzae com arroz e os mecanismos de manifestação de resistência são pontos de partida para identificar medidas alternativas de controle da brusone, econômica e ecologicamente sustentáveis. O controle de doenças através da ativação dos mecanismos de defesa intrínseco da planta mostra-se promissor e a pesquisa destes mecanismos tem sido cada vez mais estimulada para esclarecer os processos bioquímicos e moleculares envolvidos na RSA, tendo como estratégia o estudo da expressão de genes de plantas quando a resistência é induzida.

O objetivo deste trabalho foi estudar o processo de indução de resistência em plantas de arroz avaliando a capacidade de isolados avirulentos de $M$. oryzae em induzir resistência em plantas suscetíveis; verificando qual a concentração e qual o período de tempo que o isolado indutor deve anteceder o isolado virulento para elevar a expressão da resistência a níveis desejáveis.

\section{MATERIAL E MÉTODOS}

Foram realizados dois experimentos fatoriais, em condições de casa de vegetação, um com a cultivar Metica-1 e outro com a cultivar Cica- 8 , com doze tratamentos $(3 \times 4)$ e 40 repetições, utilizando-se os isolados de M. oryzae Py-435 (isolado da cultivar Cica-8) e Py-1050 (isolado da cultivar Metica). Foram semeados quatro linhas com a cv Metica-1 e quatro com a cv Cica-8 em bandejas plásticas contendo $3 \mathrm{~kg}$ de solo (5 g de N-P-K 5-30-15 + Zn e 3 gramas de sulfato de amônio no plantio $+2 \mathrm{~g}$ de sulfato de amônio em adubação de cobertura aos 18 dias após o plantio). Todos os isolados de M. oryzae (Tabela 1), foram cultivados em meio de aveiaágar durante dez dias sob luz branca contínua para promover a esporulação.

A indução da resistência nas plantas foi feita aos 18 dias após a germinação. Os isolados indutores foram pulverizados nas concentrações de 0 (água), $10^{5}, 3 \times 10^{5} \mathrm{e}$ $6 \times 10^{5}$ conídios. $\mathrm{mL}^{-1}$, e nos períodos de 24,48 e 72 horas que antecederam a inoculação com o isolado virulento, que foi inoculado na concentração $3 \times 10^{5}$ conidíos. $\mathrm{mL}^{-1}$, conforme metodologia descrita por Filippi \& Prabhu (2001).

\section{Avaliação}

As avaliações foram feitas nove dias após a inoculação do isolado virulento, determinando-se a severidade da brusone, em 20 plantas, através da porcentagem da área foliar afetada pela doença na primeira folha aberta, utilizando a escala de 10 graus de acordo com Notteghem (1981). Os resultados dos dois experimentos foram analisados pelo

TABELA 1 - Reação de isolados de Magnaporthe oryzae nas cultivares de arroz irrigado Metica-1 e Cica-8

\begin{tabular}{lll}
\hline \hline Cultivar & \multicolumn{1}{c}{ Py-435 (Isolado de Cica-8) } & Py-1050 ( Isolado de Metica-1) \\
\hline Cica-8 & Reação compatível (virulento) & Reação incompatível (avirulento) \\
& Inoculado para causar infecção & Inoculado para induzir resistência \\
Metica-1 & Reação incompatível (avirulento) & Reação compatível (virulento) \\
& Inoculado para induzir resistência & Inoculado para causar infecção \\
\hline
\end{tabular}


programa SPSS, e as médias foram comparadas pelo Teste de Tukey $(\mathrm{P} \leq 0,05)$. Os dados para análise foram transformados para arco seno $\sqrt{\mathrm{X}}$.

\section{Observação in vitro}

Folhas destacadas de Cica- 8 e Metica-1 foram arranjadas em condições de câmara úmida para posterior inoculação com $10 \mu \mathrm{L}$ de uma suspensão de conídios $\left(10^{5}\right.$ conídios. $\mathrm{mL}^{-1}$ ) dos isolados Py-435 e Py-1050. Após a inoculação, as folhas foram incubadas a $25^{\circ} \mathrm{C}$, por 48 horas. As observações microscópicas foram feitas após a fixação do tecido vegetal com uma solução de lactofenol, seguida de um processo de descoloração utilizando-se uma solução de lactofenol e etanol (1:1, vol:vol) de acordo com Oh \& Lee (2000). Nos fragmentos de tecidos inoculados foi observada a formação ou não de apressórios.

\section{RESULTADOS E DISCUSSÃO}

A resistência induzida manifestou-se na redução da área foliar afetada e no tipo de lesão em Cica-8 (Figura 1) quando tratada com o isolado indutor Py-1050, nas concentrações $6 \times 10^{5}, 3 \times 10^{5}$ e $10^{5}$ conídios. $\mathrm{mL}^{-1}$ aplicados 48 horas antes da inoculação do isolado virulento Py- 435 . $\mathrm{Na}$ testemunha, tratamento sem indução, as lesões foram esverdeadas, encharcadas, sem borda definida, com centro cinza e coalescentes (Figura 1). Nos tratamentos utilizandose a cv. Cica 8 , em que as concentrações do indutor foram de $6 \times 10^{5}$ e $3 \times 10^{5}$ conídios. $\mathrm{mL}^{-1}$ foram observados tipos de lesões semelhantes, representadas por notas 1 e 3 . As lesões do tipo 1 caracterizam-se por serem pontuais, não abertas, definidas como reação de hipersensibilidade e as lesões tipo 3 caracterizam-se por serem isoladas, de forma arredondada, com borda marrom e definida e o centro esbranquiçado. Nestes tratamentos foram observadas poucas lesões do tipo 4 que se caracterizam-se por apresentar uma forma elíptica bem definida com centro cinza ou branco. Todas as concentrações em todos os períodos de aplicação do indutor reduziram a severidade da brusone em relação à testemunha.

A análise da variância da severidade de brusone nas folhas em Cica-8 apresentou uma interação significativa entre

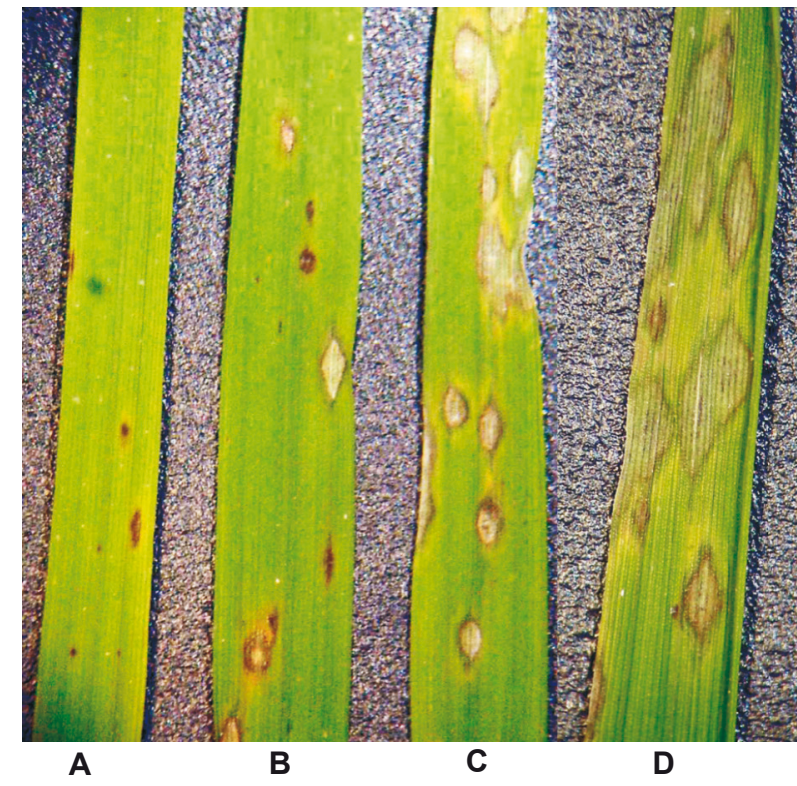

FIG. 1 - Sintomas da brusone nas folhas da cultivar Cica-8 após a indução de resistência com o indutor Py-1050 nas concentrações: A- $6 \times 10^{5}$ conídios. $\mathrm{mL}^{-1}$; B- $3 \times 10^{5}$ conídios. $\mathrm{mL}^{-1}$ e C- $10^{5}$ conídios. $\mathrm{mL}^{-1}$; D- Testemunha (água), aplicado 48 horas antes da inoculação do isolado virulento Py-435.

a concentração e o intervalo de aplicação do indutor (Tabela 2, Figura 2 C-D). A aplicação do indutor de resistência 24 e 72 horas antes da inoculação com o isolado virulento não mostrou diferença significativa entre as concentrações do indutor, embora com tendência de redução da severidade com o aumento da concentração. Por outro lado, no período de 48 horas, as concentrações do indutor de $3 \times 10^{5}$ e $6 \times 10^{5}$ conídios. $\mathrm{mL}^{-1}$ reduziram intensamente a severidade da brusone nas folhas em relação a menor concentração $\left(10^{5}\right.$ conídios. $\mathrm{mL}^{-1}$ ) (Tabela 2).

A análise de variância para Metica-1 indicou que não houve interação significativa entre a concentração e o período de aplicação do indutor (Figura 2 A-B). A indução de resistência na cv Metica-1 ocorreu em todas as concentrações,

TABELA 2 - Severidade da brusone nas folhas (\%) em relação ao período de aplicação e à concentração do indutor de resistência, na cultivar Cica-8

\begin{tabular}{|c|c|c|c|}
\hline \multirow{2}{*}{$\begin{array}{c}\text { Indutor de resistência } \\
\text { Concentração } \\
\left(\text { conídios.mL }{ }^{-1}\right)\end{array}$} & \multicolumn{3}{|c|}{$\begin{array}{l}\text { Severidade da brusone (\%) } \\
\text { Período de aplicação do indutor (horas antes da inoculação) }\end{array}$} \\
\hline & $24 \mathrm{~h}$ & $48 \mathrm{~h}$ & $72 h$ \\
\hline 0 (testemunha) & $23,05 \mathrm{a}^{1}$ & $23,05 \mathrm{a}$ & $23,05 \mathrm{a}$ \\
\hline $1 \times 10^{5}$ & $3,85 \mathrm{~b} \mathrm{~A}^{2}$ & $2,15 \mathrm{~b} \mathrm{~A}$ & $11,7 \mathrm{~b} \mathrm{~B}$ \\
\hline $3 \times 10^{5}$ & $2,48 \mathrm{~b} \mathrm{AB}$ & $0,85 \mathrm{c} \mathrm{A}$ & $4,18 \mathrm{~b} \mathrm{~B}$ \\
\hline $6 \times 10^{5}$ & $1,72 \mathrm{bB}$ & $0,3 \mathrm{cA}$ & $2,09 \mathrm{bB}$ \\
\hline
\end{tabular}

${ }^{1}$ Médias seguidas pela mesma letra minúscula na coluna não diferem significativamente pelo teste de Tukey ao nível de $5 \%$ de probabilidade; ${ }^{2}$ Médias seguidas pela mesma letra maiúscula na linha não diferem significativamente pelo teste de Tukey ao nível de $5 \%$ de probabilidade. 

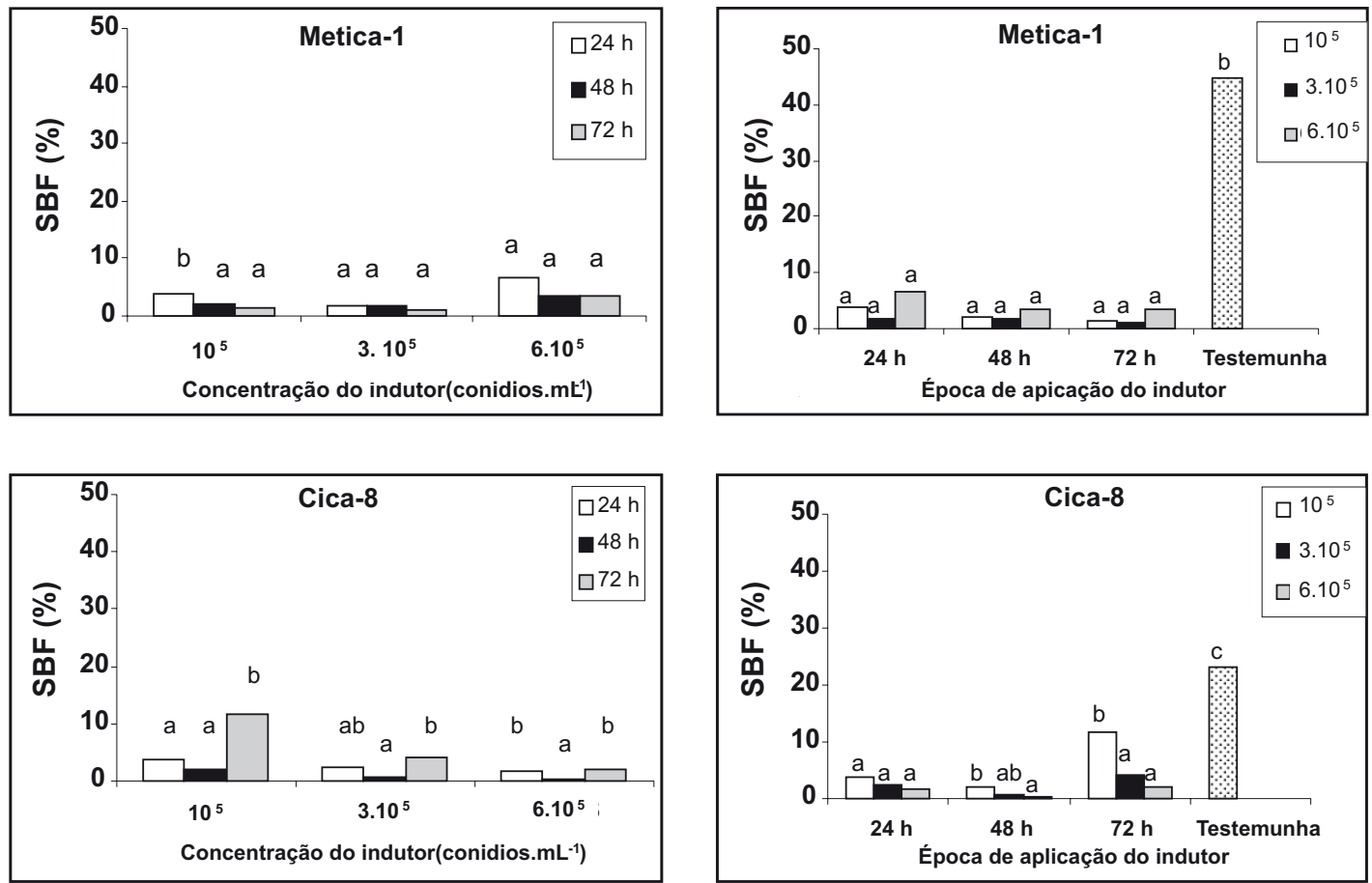

FIG. 2 - Severidade da brusone nas folhas (SBF) em relação a época de aplicação e concentração do indutor de resistência, nas cultivares Cica-8 e Metica-1.

em cada período, diferindo significativamente da testemunha (Figura 2B), entretanto as concentrações não diferiram entre si. A severidade da brusone foi menor nos períodos de 48 e 72 horas antes da aplicação do isolado virulento do que no período de 24 horas, considerando-se a concentração do indutor Py-435 de $10^{5}$ conídios. $\mathrm{mL}^{-1}$.

As observações microscópicas da inoculação in vitro indicaram que houve a formação de apressórios tanto nas interações compatíveis (Figura $3 \mathrm{~B}-\mathrm{C}$ ) como nas incompatíveis (Figura 3 A-D). Os tratamentos contavam com a presença de um gene de resistência, tanto em Cica-8 como em Metica-1, mas deve-se considerar a importância do evento de indução uma vez que para ser expresso, não exige necessariamente a especificidade de um gene de resistência.

A resistência induzida pode ser definida como uma resposta de defesa, rápida e eficaz, acionada quando a planta recebe um estímulo inicial, seja biótico ou abiótico. Sabe-se que a resistência induzida é um fenômeno que ocorre em cereais importantes como o trigo, aveia e o arroz (Gorlach et al., 1996; Zimmerli et al., 2004; Schaffrath et al., 1995; Schweizer et al., 1989). No presente trabalho foi comprovada a indução de resistência em plantas de arroz a $M$. oryzae, utilizando-se como indutor um isolado avirulento da mesma espécie. O controle da brusone com a pré-inoculação de um isolado de $M$. oryzae avirulento em arroz foi primeiramente demonstrado no Japão (Kiyosawa \& Fujimaki, 1967; Ohata \& Kozaka, 1967). Foi verificado que existe um período de tempo e uma concentração ideal para a indução da resistência, e que estes fatores mudam com a cultivar, sendo necessário um estudo para cada genótipo. Para a cultivar Metica-1, quando foi utilizada baixa concentração do indutor, foi necessário um maior intervalo de tempo entre a aplicação do indutor e a inoculação do isolado virulento para se obter níveis desejáveis de resistência (Figura 2 A-B). A mesma situação não se aplica a Cica-8, pois, somente no período de 48 horas de pulverização com o indutor foi possível diferenciar as concentrações do indutor que proporcionaram menor severidade da brusone (Figura 2 C-D). Com o aumento do período entre a aplicação do indutor e a inoculação do isolado patogênico houve aumento da severidade da brusone. Essa diferença pode ser atribuída ao menor grau de suscetibilidade de Cica8 em relação à Metica-1, constatado pelas médias da severidade da doença nas testemunhas. Foi observado que houve um gradiente de indução, isto é, quanto maior a concentração do agente indutor menor a área foliar afetada pela brusone, acompanhada de uma mudança no tipo de lesão. As lesões obtidas com a mistura de inoculação com isolados de M. oryzae avirulento e virulento foram menores do que a causada por isolados virulentos (Ohata \& Kozaka, 1967). Park \& Kim (1983), ao induzirem resistência em arroz a brusone com um isolado avirulento, obtiveram uma redução do tamanho de lesão em até $3,0 \mathrm{~cm}$, quando comparado com o tamanho da lesão formada na testemunha. De acordo com o presente trabalho, as plantas que receberam as concentrações mais altas do indutor, 

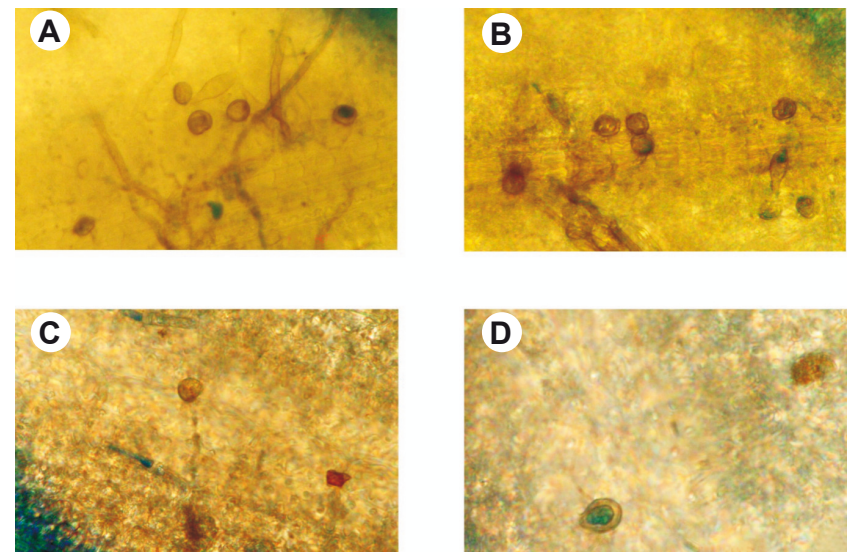

FIG. 3 - Observação microscópica de inoculação in vitro de Magnaporthe oryzae. A. Metica-1 inoculada com Py-435 (reação incompatível); B. Cica-8 inoculada com Py-435 (reação compatível); C. Metica-1 inoculada com Py-1050 (reação compatível); D. Cica8 inoculada com Py-1050 (reação incompatível).

combinadas com o intervalo de aplicação, para a cultivar Cica-8 o indutor aplicado 48 horas antes da inoculação com isolado virulento, na concentração de $6 \times 10^{5}$ conídios. $\mathrm{mL}^{-1}$ e, para a cultivar Metica 1, o indutor aplicado 72 horas antes da inoculação virulenta, na concentração de $3 \times 10^{5}$ conídios. $\mathrm{mL}^{-1}$, apresentaram lesões dos tipos 1 e 3 respectivamente, comparadas com lesões dos tipos 4 a 9 observadas nas plantas testemunhas (Figura 1). Fujita et al. (1990) ao induzirem a resistência com isolado avirulento obtiveram mais que $80 \%$ de redução da severidade da doença, resultando em lesões pequenas com margens marrons. No presente trabalho, considerando as médias de todos os tratamentos (Tabela 2 e Figura 2) as plantas tratadas com o indutor de resistência apresentaram uma redução significativa da severidade da brusone nas folhas de 93,8\% para Metica-1 (Figura $2 \mathrm{~A}$ e B) e de $85,87 \%$ para Cica-8 (Figura 2 C-D) em relação as suas respectivas testemunhas.

A redução da brusone nas folhas e panículas com aplicação de indutor de resistência biótico tem sido observada em experimentos realizados em campo (Iwano, 1987; Manandhar et al., 1998).

Hoje as medidas de controle de doenças continuam tendo em vista o potencial produtivo das cultivares melhoradas e adaptadas, como também a diminuição do impacto ambiental causado pela aplicação de defensivos em áreas extensas. Elucidar os mecanismos de RSA em arroz, em condições de laboratório, constitui-se em um desafio, mas transformar este conhecimento em novas estratégias de controle da doença, em condições de campo, é um desafio ainda maior. Em experimentos a serem realizados no futuro pretende-se induzir resistência pela aplicação do isolado de $M$. oryzae avirulento e detectar, através de ensaios enzimáticos, as principais proteínas relacionadas à patogênese presentes na indução da resistência em plantas de arroz suscetível, porém, produtiva e adaptada como Metica-1.

\section{AGRADECIMENTOS}

Marta C.C. Filippi e Anne S. Prabhu agradecem ao Conselho Nacional de Desenvolvimento Científico e Tecnológico - CNPq pela concessão de bolsa. Gisele B. Silva agradece ao Conselho Nacional de Desenvolvimento Científico e Tecnológico - CNPq/Setec-GO, pela concessão de bolsa de estudo na modalidade Desenvolvimento Regional.

\section{REFERÊNCIAS BIBLIOGRÁFICAS}

CAI, X.Z. \& ZHENG, Z. Biochemical mechanisms of salicylic acidinduced resistance in rice seedlings to blast. Acta Phytopathologica Sinica 27:231-236. 1997.

FILIPPI, M.C. \& PRABHU, A.S. Phenotypic virulence analysis of Pyricularia grisea isolates from Brazilian upland rice cultivars. Pesquisa Agropecuária Brasileira 36:27-35. 2001.

FLOR, H.H. Current status of the gene-for-gene concept. Annual Review Phytopathology 9:275-296. 1971.

FUJITA, Y., SONDA, R. \& YAEGESHI, H. Leaf blast suppression by pre-inoculation of some incompatible lesion-type isolates of Pyricularia oryzae. Phytopathological Society of Japan 56:23-275. 1990.

GORLACH, J., VOLRATH, S., KNAUF-BEITER, F., HENGRY, G., BECKHOVE, U., KOGEL, K.H., OOSTENDORP, M., STAUB, T., WARD, E., KESSMANN, H. \& RYALS, J. Benzonthiazole, a novel class of inducers of systemic acquired resistance, actives gene expression and disease resistance on wheat. Plant Cell 8:629643. 1996.

GUZZO, S.D. Aspectos bioquimícos e moleculares da resistência sistêmica adquirida em cafeeiro contra Hemileia vastatrix. Tese de Doutorado. Universidade de São Paulo - CENA. Piracicaba SP. 2004.

IWANO, M. Suppression of rice blast infection by incompatible strain of Pyricularia oryzae Cav. Bulletin of Tohoku National Agricultural Experimental Station 75:27-39. 1987.

JAROSCH, B., KOGEL, K.H. \& SCHAFFRATH, U. The ambivalence of the barley Mlo locus: Mutations conferring resistance against powdery mildew (Blumeria graminis f. sp. hordei) enhance susceptibility to the rice blast fungus Magnaporthe oryzae. Molecular Plant-Microbe Interaction 12:508-514. 1999.

KIYOSAWA, S. \& FUJIMAKI, H. Studies on mixture inoculation of Pyricularia oryzae. Effects of mixture inoculation and concentration on the formation of susceptible lesions in the injection inoculation. Bulletin of the National Institute of Agricultural Sciences 17:1-19. 1967.

KUC, J. \& STROBE, N. Induced resistance using pathogens and nonpathogens. In: Jajamos, E.G. \& Papavizas, R.C. (Eds.) Biological Control of Plant Diseases. New York. Plenum. 1992. pp. 295-303.

KUC, J. Induced systemic resistance: an Overview. In.: Hammerschmidt, R. \& Kuc, J. (Eds.) Induced Resistance to Disease in Plants. Dordrecht. Kluwer Academic Publishers. 1995. pp. 169-175.

MANANDHAR, H.J., LYNGS JORGENSEN, H.J., MATHUR, 
S.B. \& SMEDEGAARG-PETERSEN, V. Resistance to rice blast induced by ferric chloride, dipotassium hydrogen phosphate and salicylic acid. Crop Protection 17:323-329. 1998.

MANANDHAR, H.K., JORGENSEN, H.J.L., MATHUR, S.B. \& SMEDEGAARD-PETERSEN, V. Induced resistance against rice blast. In: Tharreau, D., Lebrun, N.H., Talbot, N.J. \& Notteghem, J.L. (Eds.) Advances in Rice Blast Research. Dordrecht. Kluwer Academic Publishers. 2000. pp. 93-104.

NOTTEGHEM, J. L. Cooperative experiment on horizontal resistance to rice blast. In: INTERNATIONAL RICE RESEARCH INSTITUTE (Los Baños, Filipinas). Blast and upland rice: report and recommendations from the meeting for international collaboration in upland rice improvement. Los Baños, 1981. pp. 43-51.

OH, H.S. \& LEE, Y.H. Target-site-specific screening system for antifungal compounds on appressorium formation in Magnaporthe oryzae. Phytopathology 90:1162-1168. 2000.

OHATA, K. \& KOZAKA, T. Interaction between two races of Pyricularia oryzae in lesion formation in rice plants and accumulation of fluorescent compounds associated with infection. Bulletin of the National Institute of Agricultural Sciences 21:111135. 1967.

PARK, S.K. \& KIM, K.C. Effects of mixing and reciprocal inoculation with compatible and incompatible races of Pyricularia oryzae on the enlargement of disease lesions of rice blast. Korean Journal of Plant Protection 22:300-306. 1983.

PRABHU, A.S., CASTRO, E.M., ARAUJO, L.G. \& BERNI, R.F. Resistance spectra of six elite breeding lines of upland rice to Pyricularia grisea. Pesquisa Agropecuária Brasileira 38:203-210. 2003.

RIBEIRO DO VALE, F.X., PARLEVLIET, J.E. \& ZAMBOLIM,
L. Concepts in plant disease resistance. Fitopatologia Brasileira 26:577-589. 2001.

SCHAFFRATH, U., FREYDL, E. \& DUDLER, R. Evidence for different signaling pathways actived by induces on acquired resistance in wheat. Plant Molecular 46:293-307. 1995.

SCHENK, P.M., KAZAN, K., WILSON, I., ANDERSON, J.P., RICHARMOND, T., SOMERVILE, S.C. \& MANNERS, J.M. Coordinated plant defense responses in Arabidopsis revealed by microarray analysis. Proceedings of the National Academy of Science of the USA 97:11655-11660. 2000.

SCHONEBECK, F. \& STEINER, U. Induced resistance. In: Hartleb, H., Heitefuss, R. \& Hoppe, H.H. (Eds.). Resistance of Crop Plant Against Fungi. Jena. Gustav Fischer. 1997. pp. 272-297.

SCHWEIZER, P., HUNZIGER, W. \& MÖSINGER, E. cDNA cloning, in vitro transcription and partial sequence analysis of mRNA from winter wheat (Triticum aestivum L.) with induced resistance to Erysiphe graminis f. sp. tritici. Plant Molecular Biology 12:643-654. 1989.

YANG, Z. \& DICKMAN, M.B. Colletotrichum trifolii mutants disrupted in the catalytic subunit of cAMP-dependent protein kinase are nonpathogenic. Molecular Plant Microbe Interaction 12:960-968. 1999.

ZIMMERLI, L., JAKAB, G., MÉTRAUX, J.P. \& MAUCHMANI, B. Potentiation of pathogen-specif defense mechanisms in Arabidopsis by $\beta$-aminobutiric acid. Proceedings of the National Academy of Science of the USA 161:557-568. 2004.

WANG, Z., JIA, Y., RUTGER, J.N. \& XIA, Y. Rapid survey of presence of a blast resistance gene Pi-ta in rice cultivar using the ominat DNA markers derived from portions of Pi-ta gene. Plant Breeding 126:36-42. 2007. 